\title{
Possible selves and personal goals: What can we learn from episodic future thinking?
}

\author{
Alastair Henry a * \\ a University West, Gustava Melinsgata 2, Trollhättan 461 86, Sweden
}

\begin{tabular}{l|l|l} 
Received 03 June 2020 & Received in revised form 13 August 2020 & Accepted 08 October 2020
\end{tabular}

\begin{abstract}
APA Citation:
Henry, A. (2020). Possible selves and personal goals: What can we learn from episodic future thinking? Eurasian Journal of Applied Linguistics, 6(3), 481-500.
\end{abstract}

Doi: 10.32601/ejal.834659

\begin{abstract}
Mental time travel lies at the frontier of research into motivational persistence in language learning (Dörnyei, 2020). This article introduces the theory of episodic future thinking (D'Argembeau, 2016, 2020), and examines the key components of autobiographical knowledge and personally important goals. With findings on the long-term goals and career aspirations of preservice English teachers as a departure point (Erten, 2014; Ölmez Çağlar, 2019), I outline the contributions that episodic future thinking can make to the psychology of second language learning and teaching. Positioning episodic future thinking in conceptual terrain at the intersection of vision-based theories of L2 motivation (Dörnyei, 2009), Self Determination Theory frameworks (Noels, 2009), and narrative, life-story approaches (Dörnyei \& Ryan, 2015), I explain how it can inform the investigation of motivational persistence.
\end{abstract}

(C) 2020 EJAL \& the Authors. Published by Eurasian Journal of Applied Linguistics (EJAL). This is an open-access article distributed under the terms and conditions of the Creative Commons Attribution license (CC BY-NC-ND) (http://creativecommons.org/licenses/by-nc-nd/4.0/).

Keywords: Mental time travel; episodic future thinking; self-concordant goals; autobiographical knowledge; L2 motivation; motivational persistence

\section{Introduction}

Learning a language requires sustained personal investment. So too does learning to become someone who teaches a language. Given the long-term nature of these undertakings, and the need to keep sight of one's ultimate goals over sometimes years of study, it is surprising that factors which promote or constrain motivational sustainability have not received greater attention (Dörnyei, 2020). This is an oversight equally pertaining to mainstream motivational science, where far more attention has been paid to understanding the direction and intensity of motivated effort than to motivational persistence and energy maintenance (Grant \& Shin, 2012). In recent years, however, investigations into L2 persistence have begun to take place. As well as the theory of directed motivational currents (Dörnyei, Henry \& Muir, 2016), persistence in L2 learning has prompted work with a focus on L2 grit

\footnotetext{
* Corresponding author. Tel.: +0-520-223786

E-mail address: al.henry@hv.se

http://dx.doi.org/10.32601/ejal.834659
} 
(Teimouri, Plonsky, \& Tabandeh, 2020), language mindsets (Lou \& Noels, 2019), and language learners' regulatory orientations (Henry \& Davydenko, 2020; Papi, Bondarenko, Mansouri, Feng, \& Jiang, 2019). In this article I examine research into mental time travel and future-oriented thinking (Baumeister \& Masicampo, 2010; Suddendorf \& Corballis, 2007), and consider how the imagining of future events that have personal importance can support motivational persistence in L2 learning and teaching.

Episodic future thinking is a type of self-referential prospection (imagining future situations relating to one's self) that involves the mental simulation of events expected to happen in one's life (D'Argembeau, 2016, 2020). Structured around autobiographical knowledge (mental representations that involve personality-based preferences) and personally important goals, episodic future thinking enables a person to pre-experience an anticipated event before it happens. Because imagined events that align with a person's self-knowledge, important goals, and life expectations can feel more "real" than other types of mental image, episodic future thinking can be a powerful form of prospection (Ernst \& D'Argembeau, 2017). Phenomenologically akin to the experiences conceptualized to influence behavior in Markus and Nurius' (1986) theory of possible selves, episodic future thinking is hypothesized to play an important role "in guiding and motivating actions to bring about desired future states" (D’Argembeau, 2020, p. 362). Paying particular attention to the role ascribed to personal or "self-concordant" goals (Ernst, Philippe \& D'Argembeau, 2018), and aligned with Dörnyei's (2020) conceptualizations of persistence in L2 learning, I offer insights into the central dimensions of the theory and explain how it can support our understanding of long-term motivation. Since this article forms part of a special issue dedicated to the memory of the journal's founding editor, Professor İsmail Hakkı Erten, it is fitting that this exploration should begin with research into preservice EFL teachers' professional aspirations that he initiated.

\section{The hopes and goals of Turkish EFL teachers}

Although İsmail Hakkı Erten was perhaps best known for his work on attribution and academic self-concept (e.g., Erten, 2015a; Erten \& Burden, 2014), he was also involved in important research into preservice teachers' motivations for teaching (Erten, 2014, 2015b; Ölmez Çağlar, 2019; Ölmezer Öztürk, 2015). In this work, Erten and his students were interested in understanding how preservice EFL teachers viewed their professional futures, and why they had chosen language teaching as a career path.

In a study investigating the motivation of preservice teachers of English at Çanakkale Onsekiz Mart University, Erten (2014) collected data using an instrument containing open-ended questions. With the objective of casting light on the reasons why his participants had opted for a career teaching English, Erten carried out a sequence of content analyses. Drawing on a long tradition of research highlighting intrinsic, extrinsic, and altruistic motivations as the primary groups of reasons why 
people take up teaching careers (see e.g., Brookhart \& Freeman, 1992; Richardson \& Watt, 2005, 2006), analysis revealed 20 different reasons. Intrinsic reasons were those most frequently reported. Indeed, $60 \%$ of all responses fell within this category. While extrinsic reasons accounted for $37 \%$ of the reasons, just $3 \%$ of reasons were grouped as altruistic. In the intrinsic category, five specific motivations could be discerned: interest in the field, perceived success in the field, love of teaching, teaching as a longterm goal, and fulfilling future development. Reflecting on these findings - and their importance for language teacher education in Turkey-Erten (2014) noted how "it is obvious that participants in this study like teaching and hope to have a successful life out of something they enjoy doing" (p. 40).

Under Erten's supervision, Ölmez Çağlar (2019) continued the investigation of preservice teachers' career aspirations. Inspired by the work of Kubanyiova (2009, 2014) and Hiver (2013), and using a multiphase mixed methods design, she explored the relationships between possible language teacher selves, motivations for teaching English, and the self-efficacy beliefs of students at twelve universities. Findings showed that study participants had highly developed and clearly-structured ideal, ought-to, and feared language teacher selves. Ideal selves predicted greater autonomous motivation for teaching English, which in turn predicted higher levels of self-efficacy. Examining participants' ideal teacher selves, Ölmez Çağlar found that they tended to reference personal qualities associated with longer-term goals. While some of these qualities involved a dedication to teaching, and being a creative, knowledgeable and successful professional, others were relationally-framed and encapsulated aspirations to be inspiring and student-centered in teaching. Reflecting on these results, Ölmez Çağlar emphasized the importance of preservice teachers' possible selves in shaping career aspirations and, like Erten (2014), the promising nature of the findings for EFL teacher education in Turkey.

\section{How sustainable is initial motivation?}

As these findings demonstrate, preservice teachers can begin their education with positive views of the future. For the participants in Erten and Ölmez Çağlar's studies, teaching English was a long-term goal which held the offer of a personally fulfilling career. Motivated by largely intrinsic reasons, these preservice teachers imagined themselves engaging in meaningful and enjoyable activities. They also imagined being engaged in career development and understood how in-service training could support professional competence, and thus fulfil the promise of a sustainable and successful career. At the same time, it is also clear from these studies that intrinsic motivation at the outset of a program of study, and the envisioning of a desired future state as a successful teacher, might not be sufficient in guiding behavior towards the achievement of long-term goals over the years of study needed to gain a teaching qualification.

As indicated in the introduction to this article, the theory of episodic future thinking suggests that a person's aspirations and intrinsic goals may be effective in 
sustaining motivated behavior to the extent that they become integrated parts of an imagined personal future and are aligned with personally important values and central dimensions of personality (Ernst \& D'Argembeau, 2017; Ernst et al., 2018; Ernst, Scoboria \& D'Argembeau, 2019). To understand these contentions, and to appreciate their relevance to sustainable motivation, I first outline the theory of episodic future thinking, and in particular the role played by personal goals in the simulation of future events in a person's life (D'Argembeau, 2016, 2020). Then, I suggest ways in which insights from D'Argembeau's work can be used in developing understandings of motivational persistence among people who embark on the process of learning a foreign language or becoming a teacher of a foreign language. I begin, however, by looking at how the simulation of future events is part of the human capacity for mental time travel (Michaelian, Klein \& Szpunar, 2016).

\section{Mental time travel}

Episodic future thinking (D'Argembeau, 2016, 2020) is part of the theorizing of human memory (Szpunar, 2010). Memory operates in systemic forms. While enduring facts about the world are stored in a semantic system, an episodic system facilitates the conscious recollection of past events through processes of retrospective mental time travel. Interestingly, evidence suggests that the episodic system is not only involved in retrospective time travel. In addition to creating images of events which have already taken place, the episodic system is also believed to be involved in prospective forms of mental time travel (time travel oriented towards the future) (Suddendorf \& Corballis, 2007). Whether an event is experienced (in retrospective mental time travel) or anticipated (in prospective travelling), both forms of mental time travel involve acts of conscious simulation:

Conceiving of future events, of course, involves a process of active construction of events that have not yet occurred, but the more general process of mental time travel highlights the evidence that episodic memory, too, is better conceived as a conscious act of construction, rather than a faithful re-enactment of the past. (Suddendorf, Addis, \& Corballis, 2009, p. 1317)

The ability to simulate future events based on information from the past is hypothesized to be one of the core ingredients of human thought (Suddendorf \& Corballis, 2007). As is widely recognized, mental time travel involves the construction of temporal sequences. In its prospective forms, mental time travel facilitates the simulation of realities, and the visualization of possibilities (Michaelian et al., 2016). In relation to social interaction most particularly, it enables the individual to make evaluations about alternative scenarios for future outcomes (Baumeister \& Masicampo, 2010). Seen in this way, the goal of prospection is not so much to predict how things are likely turn out. Rather, it is to "anticipate situations in which multiple outcomes are possible", and to "steer events toward the more desirable outcomes" (Baumeister, Hofmann, Summerville, Reiss, \& Vohs, 2020, p. 2). 


\section{Episodic future thinking}

Future-oriented mental time travel can take different forms (Michaelian et al., 2016). It can be related to the world in general, and to particular others in the social environment. It can also involve the individual's own personal future. In this sense, it is autobiographical in nature. One particular type of autobiographical prospection is episodic future thinking (D'Argembeau, 2016, 2020). Episodic future thinking refers to "the mental simulation of unique (one-time) events that might happen in one's personal future" (D'Argembeau, 2016, p. 200). It enables us to pre-experience an anticipated event, and to try out and experience different possibilities for the future.

In episodic future thinking, the pre-experiencing of a self-relevant event involves the individual as a character who plays a central role in a mentally simulated situation. The mental constructions of autobiographical future events will also include the actions that the individual imagines being involved in. The scenes that are played out in the mind's eye will additionally include images of particular features of the setting, the other characters involved, and the interactions that take place between the various individuals (D'Argembeau \& Van der Linden, 2004).

While it is possible to imagine the self as an actor in any mentally simulated situation or scene, research into episodic future thinking suggests that mental constructions of event representations are rarely random. Rather, the events in which we tend to imagine ourselves as protagonists are generally those that are personally important. In processes of event selection - the 'choosing' of the scenes that are played out in the mind - the conjuring of a scene is guided by the interconnected operation of autobiographical knowledge and personal goals (D'Argembeau, 2016, 2020).

Building on some two decades of research into mental prospection (D'Argembeau, Comblain, \& Van der Linden, 2003; D'Argembeau \& Mathy, 2011; D'Argembeau \& Van der Linden, 2004, 2007, 2012; Jeunehomme \& D'Argembeau, 2019; Lehner \& D'Argembeau, 2016), D'Argembeau's key contention is that for an event to be experienced as being a part of the individual's personal future, and to function effectively in guiding behavior (i.e. being frequently selected), it has to be integrated with autobiographical knowledge. Autobiographical knowledge refers to mental representations that involve personality-based preferences (e.g., for solitude or independent endeavor), general events expected to be encountered in life (e.g., graduation, marriage), and future life periods (e.g., parenthood, middle age, elderly life) (D'Argembeau, 2016, 2020; Ernst et al., 2019). Events that are linked with autobiographical knowledge are more likely to engender a sense that they are "real" (Ernst \& D’Argembeau, 2017; Scoboria, Mazzoni, Ernst, \& D’Argembeau, 2020). In addition to autobiographical knowledge, event selection is also influenced by the individual's personal goals. Goals are cognitive representations of desired states, or hoped-for outcomes (Austin \& Vancouver, 1996). Personal goals involve objectives which have particular significance for the individual (D'Argembeau, 2016, 2020). Mental representations that are structured around personal goals are hypothesized to have greater influence on goal pursuit (Ernst et al., 2018). 
In D'Argembeau's (2016, 2020) conceptualization of episodic future thinking, autobiographical knowledge and personal goals are linked together. Future-oriented images relate to the type of person that the individual hopes to become (e.g., relational and professional identities, as a mother and a teacher), and to the life achievements that they hope to accomplish (e.g., marriage, career success, parenthood, healthy old age). Explaining how episodic future thinking functions in steering behavior, D'Argembeau (2020) describes how personal goals influence the construction of event representations and, in turn, how these representations support and sustain goal pursuit:

.... episodic future thinking allows the detailed representation of specific events, plans, and outcomes that are related to higher-order personal goals, which are represented at the level of the autobiographical knowledge base and conceptual self. Thus, an important function of episodic future thinking may be to provide a detailed (quasi-experiential) representation or simulation of what it would be like to be in a desired end-state, and to mentally try out various steps and envisage potential obstacles in achieving this state. According to this view, personal goals drive and constrain future event representations, which in turn motivate and guide goal pursuit. (pp. 361-362)

Further, research by Ben Malek, Berna, and D'Argembeau (2017, 2018) indicates that people mentally construct life periods within which a particular event is placed, and that the construction of these autobiographical phases is similarly determined by personal goals. For example, the personal goal of marriage can function to delineate a particular period in a person's mental timeline. In turn, this can function to determine the subsequent spacing of other associated events. Thus, while "goals may drive the construction of a personal timeline, composed of anticipated autobiographical periods", a personal timeline can serve "to temporally organize episodic future thoughts" (Ben Malek et al., 2018, p. 203).

Given the role that episodic future thinking is hypothesized to play in steering goalfocused behavior and in the mental mapping of event sequences, an important strand of D'Argembeau's work has involved closer investigation of the functions and influences of personal goals (Ernst et. al., 2018). However, before reviewing this research, and assessing the implications for persistence in L2 learning, it is worthwhile taking a step back to consider more broadly the qualities of goals which are personally important.

\section{Goal self-concordance}

In pioneering work into the qualities of people's important goals, Sheldon and Elliot (1998) arrived at the conclusion that even if a goal is self-generated (i.e., autonomous), it might not feel truly personal. Recognizing that self-initiated goals can differ in the degree to which they align with a person's values and aspects of personality - all goals are not created equal (Ryan, Sheldon, Kasser, \& Deci, 1996)-Sheldon and Elliot 
(1998, 1999) developed a model of goal self-concordance. An extension of Deci and Ryan's (1985) theory of self-determination (SDT), self-concordance indexes the degree of personal ownership that people experience in relation to a self-generated goal.

In SDT, qualitative differences in people's motivation are conceptualized as existing on a continuum that ranges from controlled, non-internalized motivations (where actions are coerced, or carried out in order to avoid guilt), to autonomous, fullyinternalized and self-determined motivations (where actions are perceived as valuable, or are done because they are enjoyable) (Ryan \& Deci, 2017). The ownership of a goal - that is to say, the degree to which it aligns with a person's deeper values and aspirations - has particular importance in relation to longer-term undertakings. In line with the theory of goal self-concordance, it is not enough that a goal is autonomously generated or self-determined for it to be effective in supporting sustained endeavor. Rather, in order for motivation to endure over time, a goal needs also to be personally meaningful (Sheldon, 2014).

At the outset of research into the quality and effects of personal goals, Sheldon, Elliot and their colleagues focused on idiographic goals - goals that study participants themselves had identified as being important-as opposed to goals pre-defined by a researcher. Findings from this early research showed that goals which people experienced as autonomously generated were associated with positive outcomes. Conversely, goals that were experienced as externally controlled were associated with negative outcomes (Elliot, Sheldon \& Church, 1997; Sheldon, 1995; Sheldon \& Kasser, 1995). Moreover, it was found that when participants pursued goals that did not appear to be self-generated, they were likely to be less creative, and less open to new experiences. They were also more likely to experience conflicts between different liferoles. Interpreting these results, the concept of self-concordance was used to refer to goals more closely aligned with aspects of personality, and more generally relevant to personal growth. Goals that lacked a similar fit were referred to as non-concordant (Sheldon \& Kasser, 1998; Sheldon \& Elliot, 1998, 1999).

Examining goal pursuit in longitudinal designs, Sheldon and his colleagues found that people with self-concordant goals and those with non-concordant goals might not experience initial differences in goal-directed energy. However, over time, the effort of those pursuing non-concordant goals could begin to wane. Further, while at the outset of a course of action these people believed that they would be able to try hard, because their efforts were steered in directions not of their own choosing, energized goalpursuit became difficult to sustain (Sheldon \& Elliot, 1998; Sheldon \& Kasser, 1998). Subsequent studies have shown, for example, how students with self-concordant goals can be more successful in achieving their goals compared to counterparts with nonconcordant goals (Sheldon \& Elliot, 1999; Sheldon \& Houser-Marko, 2002; Sheldon \& Kasser, 1998). In an intervention study where participants identified goals for a semester, and were then coached on goal-pursuit strategies, findings showed that goal attainment was boosted only for participants whose initial goals were more selfconcordant (Sheldon, Kasser, Smith \& Share, 2002). In another study where physical health was in focus, participants who possessed self-concordant goals when enrolling 
at a health club were more likely to still hold a membership two years later (Bailis \& Segall, 2004).

Longitudinal research has also focused on the effects that goal self-concordance can have on well-being. While Sheldon and Houser-Marko (2002) found that study participants who pursued self-concordant goals experienced greater happiness when a goal was achieved, Sheldon and Cooper (2008) were able to show how the well-being of participants who pursued goals that were matched with self-construal dispositions tended to increase over time. In a study by Sheldon and Schuler (2011), participants with self-concordant goals reported higher levels of motivation, with goal selfconcordance being additionally associated with enhanced well-being.

Beyond Sheldon's own work, other researchers have demonstrated the importance of having self-concordant goals. Research has shown how self-concordant goals promote effective regulation, support implementation intentions, and are more frequently rehearsed (see e.g., Carraro \& Gaudreau, 2011; Higgins, 1996; Koestner, Otis, Powers, Pelletier, \& Gagnon, 2008; Milyavskaya, Inzlicht, Hope, \& Koestner, 2015). For example, in a three-year longitudinal study of Finnish upper secondary students' school engagement, Vasalampi, Salmela-Aro, and Nurmi (2009) could show that when achievement goals were also self-concordant, greater effort was invested in attaining the goal, which was revealed in enhanced goal-directed progress and increased engagement.

\section{Self-concordant goals and episodic future thinking}

To return to D'Argembeau's work on episodic future thinking, in a study exploring the influence of motivational sources underlying goal pursuit, connections between goal types (self-concordant and non-concordant) and mental representations of associated future events were investigated (Ernst et al., 2018). In this study, participants were invited to identify six personal projects associated with different goal orientations. They were told that three of these projects should be primarily driven by self-concordant motives, and that the other three should be driven by nonself-concordant motives. Next, participants were asked to generate a future event association for each of these six goals. Having generated the six future events, participants were then asked to imagine each event with as much elaboration as possible, and to include detail about, for example, location, actions, people, objects, and emotions.

Comparing the qualities of prospective thinking prompted by these varying goals, findings showed that goal self-concordance facilitated the imagining of future events, and that it could enhance the sense of "realness" attaching to a mental image. When a future event was connected with a self-concordant goal, the sense of pre-experiencing the imagined event tended to be stronger. So too did the belief that the event would actually occur. Moreover, future events associated with self-concordant goals were also rated as more effectively fulfilling the basic psychological needs of autonomy, competence and relatedness (Ryan \& Deci, 2000) than was the case for events 
associated with goals that lacked self-concordance. Similarly, there was also a stronger sense of the imagined event being integrated with identity motives, such as self-esteem, self-efficacy, distinctiveness, belonging, and meaning. Further, the connection of the imagined event with a self-concordant goal also strengthened the emotional loading of the event, and the emotional intensity of future thoughts.

Reflecting on the finding that goal self-concordance may enhance the feeling of pre-experiencing the future, and linking this result to the central concept of autobiographical knowledge (D'Argembeau, 2016, 2020), Ernst and colleagues (2018, p. 33) offer three propositions about why the imagining of a self-concordant future event can positively influence behavior directed to goal pursuit:

- The connection with autobiographical knowledge may contribute to the personal ownership of imagined events. This can have the effect that the represented content is perceived as referring to something actually happening in the individual's personal future.

- The sense of realness that can attach to an imagined event may increase motivation. It can support and guide actions towards attaining desired future states.

- Goal self-concordance may increase the subjective value of imagined events. This can promote regulation, and lead to goal achievement.

Concluding their article, Ernst et al. (2018) identify three avenues for continued research into the role of goal self-concordance in episodic future thinking: investigation of the adaptive function of episodic future thinking in goal pursuit, consideration of whether self-concordance influences event representations that encompass process simulations, and exploration of how the self-concordance of imagined future events can be enhanced through focused interventions.

\section{Exploring motivational persistence in L2 learning and teaching}

Mental time travel and self-referential thinking form a vibrant area within the psychology of the imagination (Michaelian et al., 2016). Doubtless work will be carried out within each of the avenues identified by Ernst and her colleagues (2018). In our field however, mental time travel provides a novel lens through which motivational persistence can be explored (Dörnyei, 2020). While episodic future thinking and goal self-concordance can provide important components in broadly-scoped programs exploring perseverance in L2 learning - for example in conjunction with regulatory orientations (Papi et al., 2019) or language mindsets (Lou \& Noels, 2019) - in the sections that follow I outline three more narrowly-focused directions for investigating durability in L2 motivation. First, research could investigate the adaptive processes associated with mental time travel and the pursuit of self-concordant goals in L2 learning, and the qualities of the motivated behaviors with which they are linked. Second, given the paucity of research into the imagery content of idealized representations of future language use, and the long-standing recognition of the need for ideal L2 selves to contain process imagery, research could investigate the 
construal characteristics of possible selves that are closely associated with personally important goals. Finally, given the extensive work so far carried out in developing programs of imagery training and vision-based interventions, research could investigate the ways in which autobiographical knowledge and goal self-concordance can be incorporated into motivation-enhancing frameworks.

\subsection{Adaptive processes, and the qualities of motivated behavior}

The first direction for continued research identified by Ernst and colleagues (2018) involves the adaptive function of episodic future thinking in goal pursuit. Just as selfinitiated goals are not all equal, neither is goal pursuit (Ryan et al., 1996; Sheldon, 2014). Underscoring how findings from their study support the contention that "prospection is fundamentally pragmatic and serves to guide actions to bring about desired future states" (p. 35) and pointing to evidence suggesting that episodic future thoughts refer to events that generally do occur, Ernst and colleagues (2018) emphasize the importance of longitudinal work that can investigate the influences of episodic future thinking on goal pursuit.

In the L2 context, the need to investigate the qualities of motivated behavior has previously been emphasized by Papi and colleagues (Papi, 2018; Papi et al., 2019). Arguing that in SLA researchers "have predominantly approached motivation as a quantity of energy that is produced to initiate, continue, and complete the learning pursuit", Papi (2018, p. 707) underscores the importance of investigating the quality of learners' motivation, and the influences on regulation. Similarly, Al-Hoorie (2018) makes the point that there exist different dimensions of motivated behavior, an important distinction being between agentic and non-agentic behavior. As he makes clear, effort "that is planful and purposeful should count as more than the effort that merely reflects norm following" (p. 741).

In an interesting development-and part of the current focus on student engagement (Hiver, Al-Hoorie \& Mercer, 2021; Mercer \& Dörnyei, 2020)—research has also begun to investigate qualitative differences in L2 learners' focused behavior (Oga-Baldwin, 2019). Here, a model of engagement which has attracted significant interest is Reeve's $(2012,2013)$ conceptualization of four interrelated aspects of student engagement. In addition to behavioral, cognitive and emotional dimensions, Reeve's model involves an agentic element. As Reeve (2012) explains, engaged behavior may not only involve positive reactions to a learning task-for example where a learner demonstrates enjoyment, persistence and strategic thinking. It can also involve an agentic dimension, where the student "generates options that expand his or her freedom of action and increase the chance for that student to experience both strong motivation and meaningful learning" (p. 162). In forms of agentic engagement, students are not only cognitively and emotionally engaged in learning tasks; they are also proactively involved in creating, enriching and personalizing the activities they work with. As Reeve (2013, p. 591) explains, agentically engaged 
students undertake "achievement facilitating action during learning activities that is above and beyond their applications of effort, enthusiasm, and strategic thinking".

When L2 learners pursue goals that are self-concordant, and which are phenomenologically linked to events expected to occur in their personal futures, engagement might be expected to be more characteristically agentive (e.g., Vasalampi, Salmela-Aro \& Nurmi, 2009). In work exploring student engagement in relation to perseverance in L2 learning, an important strand would therefore involve examination of the qualities of learners' goals. In such work, and using for example Reeve's (2012, 2013) multi-dimensional conceptualization of student engagement, it would be of value to consider whether, over time, engagement associated with the pursuit of self-concordant goals differs in quality from engagement relating to goals that are merely intrinsic. Equally, similar associations with strongly and weakly personalized images of future L2 use could be usefully explored.

\subsection{Self-regulatory possible selves}

Another research direction identified by Ernst and colleagues (2018) concerns the question as to whether self-concordance influences event representations that encapsulate process simulations. That is, whether in addition to the attainment of a goal (an outcome simulation), representations also encompass simulations of the steps needed to arrive at this end-point. This is an important question. As Ernst et al., (2018) make clear, "previous studies have shown that merely focusing and fantasizing on desired outcomes without considering potential obstacles can have negative consequences for goal attainment" (p. 35). In this respect, Ernst and colleagues draw attention to the concept of self-regulatory possible selves (Hoyle \& Sherrill, 2006), and the distinction between possible selves that represent self-enhancing, and selfdefining goals:

The construct of goal self-concordance is conceptually related to the notion of possible selves (Markus \& Nurius, 1986), and more specifically selfregulatory possible selves (i.e., possible selves that represent a self-defining goal and include specific behavioral strategies for pursuing this goal; Hoyle \& Sherrill, 2006). (Ernst et al., 2018, p. 27)

According to Hoyle and Sherrill (2006), possible selves can relate to goals that are self-defining as well as goals that are merely self-enhancing. Although a selfenhancing goal can generate positive feelings about the self, it may not have immediate and direct relevance for focused behavior. A goal that is self-defining, on the other hand, is likely to generate more consistently strategic forms of regulation. As Hoyle and Sherrill (2006) explain:

Self-regulatory possible selves are those that represent a self-defining goal and include specific behavioral strategies for pursuing the goal. Selfregulatory possible selves can be distinguished from self-enhancing possible selves, which contribute to positive feelings about the self but do not have direct relevance for current behavior. For instance, academic possible selves 
that envision the self studying and avoiding distractions are likely to motivate current behavior, whereas those that envision the self simply as a high school graduate might engender positive feeling about the self but are not likely to motivate current behavior. (p. 1677)

In Dörnyei's (2009) work developing the L2 Motivational Self System (L2MSS) model, he makes clear that an ideal L2 self is likely to be effective to the degree that it forms "part of a 'package' consisting of an imagery component and a repertoire of appropriate plans, scripts and self-regulatory strategies" (p. 37). Subsequently, researchers such as Hessel (2015) and Al-Hoorie (2018) have similarly highlighted the need for an ideal to self to contain process imagery-representations of implementation actions - if it is to function effectively in generating and guiding motivated behavior. However, while at the outset of work investigating language learners' self-concept discrepancies, MacIntyre and colleagues (2009, p. 56) made the point that "future research would do well to look at how clear the implementations are", few studies have examined the ways in which learners construe their L2 selves. Nor has research investigated the extent to which representations might encompass process imagery depicting routes and obstacles. Given the findings of research into episodic future thinking, and the particular functions of self-concordant goals (Ernst et al., 2018), an issue worthy of focused investigation would be to examine whether differences in the construal of ideal L2 selves relate to the quality of the learner's goals and associated patterns of regulation (Henry \& Davydenko, 2020; Papi, 2018; Papi et al., 2019), and, further, whether event representations that involve the pursuit of self-concordant goals contain implementation imagery to a greater degree than goals that are simply intrinsic.

\subsection{Incorporating episodic future thinking into vision-focused interventions}

The third research direction identified by Ernst and colleagues (2018) involves exploring ways of enhancing the self-concordance of imagined future events. In the context of Dörnyei's (2020) development of a theory of L2 vision, and the volume of work directed to developing techniques for enhancing visionary capacity in intervention programs, this constitutes an important pathway along which continuing work could be directed.

As is well-documented, the reinterpretation of L2 motivation effectuated in Dörnyei's (2009) L2MSS model was not simply a response to the problems associated with integrativeness (Gardner, 1985), but also a resource for supporting learner motivation. While first-generation intervention studies drew on vision-development programs from mainstream motivational science to create L2 vision-enhancing strategies, second-generation studies have implemented Dörnyei and Kubanyiova's (2014) multi-stage visionary training program in robust quasi-experimental designs. In these methodologically more exacting studies - carried out in contexts as diverse as Chile, Germany and Iran, and with learners of varying ages - promising results have been obtained, with intervention groups scoring consistently better on post-test 
measures (Busse, Cenoz, Dalmann \& Rogge, in press; Safdari, in press; Sato, in press; Sato \& Lara, 2019).

In a particularly interesting study, Munezane (2015) explored the effects of visualization and goal-setting on willingness to communicate (WTC) (a high-evidence correlate of L2 motivation; Elahi, Khajavy, MacIntyre, \& Taherian, 2019). In this study, two intervention conditions were incorporated. In one intervention group, participants worked with visualization techniques only. In the other group, visualization was combined with goal-setting activities. Here, students considered what they wanted to achieve in their lives, and how learning English fitted with these goals. Results showed that when visualization was combined with goal-setting activities, effects on WTC were significantly enhanced. This was true in comparison with both the control group (no intervention), and the visualization-only group.

Because it demonstrates the importance of incorporating exploration of personal goals within programs of vision-enhancement, Munezane's study is particularly relevant in the context of the current discussion. In their study, Ernst and colleagues (2018) emphasize the importance of integrating imagined future events with autobiographical knowledge and point to a range of studies where cognitive techniques - for example, reflecting on the degree of ownership of a goal, and the goal's intrinsic and affective values - have successfully fostered goal self-concordance (Job \& Brandstätter, 2009; Lekes, Hope, Gouveia, Koestner, \& Philippe, 2012; Sheldon et al., 2002). Therefore, in the continuing development of motivational interventions in SLA, an important innovation would involve the interweaving of images of an L2-speaking or an L2-teaching self with representations of abstracted knowledge about the self in the context of projected life events. In such holistically framed interventions, a 'self-in-the-future' image would not be "represented in isolation" (D'Argembeau, 2020, p. 360), but would instead constitute a particular component within higher-order themes and sequences. In line with findings by Hiver and his colleagues (2019), who drew on McAdams' (2006) life story theorizing to show how "language learners construct overarching narratives of the L2 learning experience" (p. 102), interventions could usefully include opportunities for participants to position an event image in the context of an extended life narrative (McAdams, 2012). In this way, a language-speaking or a language-teaching self could become an integrated part of a personalized L2 autobiography.

\section{Conclusion}

I began this article by examining research from Turkey into the motivations of preservice English teachers embarking on their careers, and which shows how they do so with a positive outlook and expectations of being engaged in work that they hope will be meaningful, enjoyable and fulfilling (Erten, 2014; Ölmez Çağlar, 2019). While findings revealed that these participants had intrinsic goals and ideal teacher selves which referenced important personal qualities, the authors caution that patterns of development vary over time, and that dreams and aspirations are shaped by current 
experiences and conditions. Intrinsic motivation, and an idealized image of a future teacher self at the start of the learning process might therefore be best understood as initial conditions that are conducive to achieving such goals and enabling a preservice teacher to "have a successful life out of something they enjoy doing" (Erten, 2014, p. 40).

However, as Dörnyei (2020) has noted, we know very little about motivational trajectories through programs of learning, or the ways in which ideal L2 selves and ideal teacher selves develop over time. We also know very little about the goals associated with becoming an L2 speaker or an L2 teacher, how these goals might interact with future visions, or the ways that goal formulations, regulation, and engagement in learning change with the passing of time. Describing the exploration of persistence in L2 learning as a "debt" that motivation research "still owes to the teaching profession" (p. 137), Dörnyei (2020) argues that it is imperative that investigations take place into the ways that patterns of regulation relate to visions of future activities involving language use, and to the goals that learners pursue.

Practicalities aside, the research which Dörnyei (2020) views as necessary in order to repay this debt presents the field with a major challenge. So far, hardly any attention has been paid to the examination of language learners' goals. As McEown and Oga-Baldwin (2019) tellingly observe, while it is widely assumed that the qualities of language learners' goals will influence regulation and persistence in goalpursuit, and while there are obvious connections between learners' goal orientations and constructs such as integrativeness and the ideal L2 self, there is almost no dedicated research on these topics. As they make clear, L2 motivation researchers interested in "translating, localizing, or otherwise replicating the work done on goals [in motivational science] have an open, but theoretically and empirically grounded, field for exploration" (p. 7).

Reviewing the research on episodic future thinking (D'Argembeau, 2016, 2020), and in particular the role played by self-concordant goals in guiding action towards desired future outcomes, it is apparent that many of the insights generated in this body of work are relevant to the investigation of perseverance in L2 learning and can support conceptualizations of L2 motivation that move beyond understandings of the direction and intensity of effort (Dörnyei, 2020). Moreover, because episodic future thinking integrates the psychologies of goal pursuit and self knowledge into theories of mental time travel, it occupies conceptual terrain at the intersection between vision-based theories of motivation (Markus \& Nurius, 1986), SDT-based frameworks (Deci \& Ryan, 1985), and narrative approaches (McAdams, 2006). Viewed in this way, it provides L2 motivation research with a concept that can create potentially unique synergies, facilitating empirical investigation by bridging between approaches based on self-concept discrepancies (Dörnyei, 2009), intrinsic-extrinsic orientations (Noels, 2009), and narrative modes of inquiry (Dörnyei \& Ryan, 2015). In highlighting the positive influences on well-being of goal self-concordance in self-referential thought, episodic future thinking also has potential to contribute to the emerging positive psychology paradigm in SLA (MacIntyre, Gregersen \& Mercer, 2016, 2019). Equally, 
the investigation of interconnections between episodic future thinking and the emotions associated with sustained motivation for L2 learning and teaching provides a further important area for research (Dewaele, 2020; MacIntyre, Ross \& Clément, 2020).

At the same time, candidate concepts from other disciplines of psychology need to be closely evaluated before being incorporated into the L2 field. We need to proceed with caution when extrapolating from the findings of work carried out in divergent theoretical disciplines and derived using methodologies not generally common in our own field. We need to carefully evaluate the utility of a theory or construct, both in relation to its potential to explain a unique, and for SLA relevant motivational phenomenon (Lou \& Noels, 2020), and in relation to the ways it can inform motivational practice. We need also to apply the construct intelligently, using methodologies that are suited to the investigation of targeted phenomena. While there are findings which indicate promising possibilities for supporting language learners in selecting personally appropriate goals (Ernst et al., 2018; Sheldon, Prentice \& Osin, 2019), and in positioning imagined future events within an autobiographical life story context (Ben Malek et al., 2017, 2018), contributions from episodic future thinking can be evaluated only once empirical work in contexts of language learning and teaching has taken place. Hopefully, this review will inspire such work.

\section{Conflict of Interest Statement}

In line with the statement of Committee on Publication Ethics (COPE), I hereby declare that I had no conflicting interests regarding any parties of this study.

\section{References}

Al-Hoorie, A. H. (2018). The L2 motivational self system: A meta-analysis. Studies in Second Language Learning and Teaching, 8, 721-754.

Austin, J. T., \& Vancouver, J. B. (1996). Goal constructs in psychology: Structure, process, and content. Psychological Bulletin, 120, 338-375.

Bailis, D. S., \& Segall, A. (2004). Self-determination and social comparison in a healthpromotion setting. Basic and Applied Social Psychology, 26, 25-33.

Baumeister, R. F., Hofmann, W., Summerville, A., Reiss, P. T. \& Vohs, K. D. (2020). Everyday thoughts in time: Experience sampling studies of mental time travel. Personality and Social Psychology Bulletin, 1-18. doi: 10.1177/0146167220908411

Baumeister, R. F., \& Masicampo, E. J. (2010). Conscious thought is for facilitating social and cultural interactions: How mental simulations serve the animal-culture interface. Psychological Review, 117, 945-971.

Ben Malek, H., Berna, F., \& D'Argembeau, A. (2017). Reconstructing the times of past and future personal events. Memory, 25(10), 1402-1411.

Ben Malek, H., Berna, F., \& D'Argembeau, A. (2018). Envisioning the times of future events: The role of personal goals. Consciousness and Cognition 63, 198-205.

Brookhart, S. M., \& Freeman, D. J. (1992). Characteristics of entering teacher candidates. Review of Educational Research, 62, 37-60. 
Busse, V., Cenoz, J., Dalmann, N., \& Rogge, F. (in press). Addressing linguistic diversity in the language classroom in a resource-oriented way: An intervention study with primary school children. Language Learning, 70(2), 382-419.

Carraro, N., \& Gaudreau, P. (2011). Implementation planning as a pathway between goal motivation and goal progress for academic and physical activity goals. Journal of Applied Social Psychology, 41(8), 1835-1856.

Dewaele, J.-M. (2020). What psychological, linguistic and sociobiographical variables power EFL/ESL teachers' motivation? In C. Gkonou, C., J.-M. Dewaele, \& J. King (Eds.), The emotional rollercoaster of language teaching (pp. 269-287). Bristol: Multilingual Matters.

D'Argembeau, A. (2016). The role of personal goals in future-oriented mental time travel. In K. Michaelian, S. B. Klein, \& K. K. Szpunar (Eds.), Seeing the Future. Theoretical perspectives on future-oriented mental time travel (pp. 199-214). New York, NY: Oxford University Press.

D'Argembeau, A. (2020). Imagination and self-referential thinking. In A. Abraham (Ed.), The Cambridge Handbook of the Imagination (pp.354-372). Cambridge: Cambridge University Press.

D’Argembeau, A., Comblain, C., \& Van der Linden, M. (2003). Phenomenal characteristic of autobiographical memories for positive, negative, and neutral events. Applied Cognitive Psychology, 17, 281-294.

D’Argembeau, A., \& Mathy, A. (2011). Tracking the construction of episodic future thoughts. Journal of Experimental Psychology: General, 140, 258-271.

D'Argembeau, A., \& Van der Linden, M. (2004). Phenomenal characteristics associated with projecting oneself back into the past and forward into the future: Influence of valence and temporal distance. Consciousness and Cognition, 13, 844-858.

D'Argembeau, A., \& Van der Linden, M. (2007). Emotional aspects of mental time travel. Behavioral and Brain Sciences, 30(3), 320-321.

D’Argembeau, A., \& Van der Linden, M. (2012). Predicting the phenomenology of episodic future thoughts. Consciousness and Cognition, 21, 1198-1206.

Deci, E. L., \& Ryan, R. M. (1985). Intrinsic motivation and self-determination in human behaviour. New York: Plenum.

Dörnyei, Z. (2009). The L2 Motivational Self System. In Z. Dörnyei \& E. Ushioda (Eds.), Motivation, language identity and the L2 self (pp. 9-42). Bristol: Multilingual Matters.

Dörnyei, Z. (2020). Innovations and challenges in language learning motivation. London: Routledge.

Dörnyei, Z., Henry, A., \& Muir, C. (2016). Motivational currents in language learning: Frameworks for focused interventions. New York: Routledge.

Dörnyei, Z., \& Kubanyiova, M. (2014). Motivating learners, motivating teachers: Building vision in the language classroom. Cambridge: Cambridge University Press.

Dörnyei, Z., \& Ryan, S. (2015). The psychology of the language learner revisited. New York: Routledge.

Elahi, M., Khajavy, G. H., MacIntyre, P. D., \& Taherian, T. (2019). A meta-analysis of L2 willingness to communicate and its three high-evidence correlates. Journal of Psycholinguistic Research, 48, 1241-1267.

Elliot, A. J., Sheldon, K. M., \& Church, M. (1997). Avoidance personal goals and subjective well-being. Personality and Social Psychology Bulletin, 23, 915-927.

Ernst, A., \& D’Argembeau, A. (2017). Make it real: Belief in occurrence within episodic future thought. Memory \& Cognition, 45, 1045-1061. 
Ernst, A., Philippe, F. L., \& D'Argembeau, A. (2018). Wanting or having to: The influence of goal self-concordance on the representation of personal future events. Consciousness and Cognition, 66, 26-39.

Ernst, A., Scoboria, A., \& D'Argembeau, A. (2019). On the role of autobiographical knowledge in shaping belief in the future occurrence of imagined events. Quarterly Journal of Experimental Psychology, 72(11), 2658-2671.

Erten, İ. H. (2014). Understanding the reasons behind choosing to teach English as a foreign language. Novitas ROYAL (Research on Youth and Language), 8(1), 30-44.

Erten, I. H. (2015a). Age-related gender differences in casual attributions of Turkish learners of English as a foreign language. ELT Research Journal, 4(2), 129-146.

Erten, İ. H. (2015b). Social desirability bias in altruistic motivation for choosing teaching as a career. Hacettepe Üniversitesi Eğitim Fakültesi Dergisi [Hacettepe University Journal of Education], 30(1), 77-89.

Erten, I. H. \& Burden, R. L. (2014). The relationship between academic self-concept, attributions, and L2 achievement. System, 42, 391-401.

Gardner, R. C. (1985). Social psychology and second language learning: The role of attitudes and motivation. London: Edward Arnold.

Grant, A. M., \& Shin, J. (2012). Work motivation: Directing, energizing, and maintaining effort (and research) In R. M. Ryan (Ed.), The Oxford handbook of human motivation (pp. 505519). New York: Oxford University Press.

Henry, A., \& Davydenko, S. (2020). Thriving? Or surviving? An approach-avoidance perspective on adult language learners' motivation. The Modern Language Journal, 104(2), 363-380.

Hessel, G. (2015). From vision to action: Inquiring into the conditions for the motivational capacity of ideal second language selves. System, 52, 103-114.

Higgins, E. T. (1996). Knowledge activation: Accessibility, applicability, and salience. In E. T. Higgins, \& A. W. Kruglanski (Eds.). Social psychology: Handbook of basic principles (pp. 133-168). New York, NY: Guilford Press.

Hiver, P. (2013). The interplay of possible language teacher selves in professional development choices. Language Teaching Research, 17(2), 210-227.

Hiver, P., Al-Hoorie, A. H., \& Mercer, S. (2021). Student engagement in the language classroom. Bristol: Multilingual Matters.

Hiver, P., Obando, G., Sang, Y., Tahmouresi, S., Zhou, A., \& Zhou, Y. (2019). Reframing the L2 learning experience as narrative reconstructions of classroom learning. Studies in Second Language Learning and Teaching, 9(1), 83-116.

Hoyle, R. H., \& Sherrill, M. R. (2006). Future orientation in the self-system: Possible selves, self-regulation, and behavior. Journal of personality, 74(6), 1673-1696.

Jeunehomme, O., \& D'Argembeau, A. (2019). The time to remember: temporal compression and duration judgments in memory for real-life events. Quarterly Journal of Experimental Psychology, 72(4), 930-942.

Job, V., \& Brandstätter, V. (2009). Get a taste of your goals: Promoting motive-goal congruence through affect-focus goal fantasy. Journal of Personality, 77(5), 1527-1559.

Koestner, R., Otis, N., Powers, T. A., Pelletier, L., \& Gagnon, H. (2008). Autonomous motivation, controlled motivation, and goal progress. Journal of Personality, 76(5), 12011230.

Kubanyiova, M. (2009). Possible selves in language teacher development. In Z. Dörnyei \& E. Ushioda (Eds.), Motivation, language identity and the L2 self (pp. 314-332). Bristol, UK: Multilingual Matters. 
Kubanyiova, M. (2014). Motivating language teachers: Inspiring vision. In D. Lasagabaster, A. Doiz, \& J. M. Sierra (Eds.), Motivation and foreign language learning: From theory to practice (pp. 71-89). Amsterdam: John Benjamins.

Lehner, E., \& D'Argembeau, A. (2016). The role of personal goals in autonoetic experience when imagining future events. Consciousness and Cognition, 42, 267-276.

Lekes, N., Hope, N. H., Gouveia, L., Koestner, R., \& Philippe, F. L. (2012). Influencing value priorities and increasing well-being: The effects of reflecting on intrinsic values. The Journal of Positive Psychology, 7(3), 249-261.

Lou, N. M. \& Noels, K. A. (2019). Promoting growth in foreign and second language education: A research agenda for mindsets in language learning and teaching. System, 86, 102126.

Lou, N. M., \& Noels, K. A. (2020). Language mindsets, meaning-making, and motivation. In M. Lamb, K. Csizér, A. Henry \& S. Ryan (Eds.), The Palgrave handbook of motivation for language learning (pp. 537-559). Basingstoke: Palgrave Macmillan.

MacIntyre, P. D., Gregersen, T., \& Mercer, S. (2016). Positive psychology in SLA. Bristol: Multilingual Matters.

MacIntyre P. D., Gregersen T. \& Mercer S. (2019). Setting an agenda for positive psychology in SLA: Theory, practice, and research. The Modern Language Journal, 103(1), 262-274.

MacIntyre, P. D., Mackinnon, S. P., \& Clément, R. (2009). The baby, the bathwater, and the future of language learning motivation research. In Z. Dörnyei \& E. Ushioda (Eds.), Motivation, language identity and the L2 self (pp. 43-65). Bristol, UK: Multilingual Matters.

MacIntyre, P. D., Ross, J., \& Clément, R. (2020). Emotions are motivating. In M. Lamb, K. Csizér, A. Henry \& S. Ryan (Eds.), Palgrave handbook of motivation for language learning (pp. 183-202). Basingstoke: Palgrave Macmillan.

Markus, H., \& Nurius, P. (1986). Possible selves. American psychologist, 41, 954-969.

McAdams, D. P. (2006). The role of narrative in personality psychology today. Narrative Inquiry, 16, 11-18.

McAdams, D. P. (2012). Exploring psychological themes through life narrative accounts. In J. A. Holstein, \& J. F. Gubrium (Eds.), Varieties of narrative analysis (pp. 15-32). London: SAGE.

McEown, M. S., \& Oga-Baldwin, W.L.Q. (2019). Self-determination for all language learners: New applications for formal language education. System, 86, 102124.

Munezane, Y. (2015). Enhancing willingness to communicate: Relative effects of visualization and goal setting. The Modern Language Journal, 99, 175-191.

Mercer, S., \& Dörnyei, Z. (2020). Engaging language learners in contemporary classrooms. Cambridge: Cambridge University Press.

Michaelian, K., Klein, S. B., \& Szpunar, K. K. (Eds.). (2016). The past, the present, and the future of future-oriented mental time travel: Editors' introduction (pp. 1-22). New York: Oxford University Press.

Milyavskaya, M., Inzlicht, M., Hope, N., \& Koestner, R. (2015). Saying "no" to temptation: Want-to motivation improves self-regulation by reducing temptation rather than by increasing self-control. Journal of Personality and Social Psychology, 109(4), 677-693.

Noels, K. A. (2009). Identity and the internalization of language learning into the self-concept. In Z. Dörnyei \& E. Ushioda (Eds.), Motivation, language identity and the L2 self (pp. 295313). Clevedon, UK: Multilingual Matters.

Oga-Baldwin, W.L.Q. (2019). Acting, thinking, feeling, making, collaborating: The engagement process in foreign language learning. System, 86, 102128. 
Ölmez Çağlar, F. (2019). Relationships among possible selves, motivations and self-efficacy beliefs of senior student teachers of English (Unpublished $\mathrm{PhD}$ thesis). Hacettepe University, Turkey.

Ölmezer Öztürk, E. (2015). A qualitative study on the motivation of Turkish EFL teachers working at state universities. Journal of Theory and Practice in Education, 11(4), 14361453.

Papi, M. (2018). Motivation as quality: Regulatory fit effects on incidental vocabulary learning. Studies in Second Language Acquisition, 40, 707-730.

Papi, M., Bondarenko, A. V., Mansouri, S., Feng, L., \& Jiang, C. (2019). Rethinking L2 motivation research: The $2 \times 2$ model of L2 self-guides. Studies in Second Language Acquisition, 41, 337-361.

Reeve, J. (2012). A self-determination theory perspective on student engagement. In S.L. Christenson, A.L. Reschly, \& C. Wylie (Eds.), Handbook of research on student engagement (pp.149-172). New York: Springer.

Reeve, J. (2013). How students create motivationally supportive learning environments for themselves: The concept of agentic engagement. Journal of Educational Psychology 105(3), $579-595$.

Richardson, P.W., \& Watt, H.M.G. (2005). I have decided to become a teacher: influences on career change. Teaching and Teacher Education, 21, 475-489.

Richardson, P.W., \& Watt, H.M.G. (2006). Who chooses teaching and why? Profiling characteristics and motivation across three Australian Universities. Asia-Pacific Journal of Teacher Education, 34, 27-56.

Ryan, R. M., \& Deci, E. L. (2000). Self-determination theory and the facilitation of intrinsic motivation, social development, and well-being. American Psychologist, 55, 68-78.

Ryan, R. M., \& Deci, E. L. (2017). Self-Determination theory: Basic psychological needs in motivation, development, and wellness. New York: The Guilford Press.

Ryan, R. M., Sheldon, K. M., Kasser, T., \& Deci, E. L. (1996). All goals are not created equal: The relation of goal content and regulatory styles to mental health. In J. A. Bargh \& P. M. Gollwitzer (Eds.), The psychology of action: Linking cognition and motivation to behavior (pp. 7-26). New York: The Guilford Press.

Safdari, S. (in press). Operationalizing L2 motivational self system: Improving EFL learners' motivation through a vision enhancement program. Language Teaching Research. https://doi.org/10.1177/1362168819846597.

Sato, M. (in press). Generating a Roadmap for Possible Selves via a Vision Intervention: Alignment of Second Language Motivation and Classroom Behavior. TESOL Quarterly. https://doi.org/10.1002/tesq.611.

Sato, M., \& Lara, P. (2019). Interaction vision intervention to increase second language motivation: A classroom study. In M. Sato \& S. Loewen (Eds.), Evidence-based second language pedagogy: A collection of instructed second language acquisition studies (pp. 287313). New York, NY: Routledge.

Scoboria, A., Mazzoni, G., Ernst, A., \& D'Argembeau, A. (2020). Validating "belief in occurrence" for future autobiographical events. Psychology of Consciousness: Theory, Research, and Practice, 7(1), 4-29.

Sheldon, K. M. (1995). Creativity and self-determination in personality. Creativity Research Journal, 8, 61-72.

Sheldon, K. M. (2014). Becoming oneself. Personality and Social Psychology Review, 18(4), 349365. 
Sheldon, K. M., \& Cooper, M. L. (2008). Goal striving within agentic and communal roles: Functionally independent pathways to enhanced well-being. Journal of Personality, 76, 415-447.

Sheldon, K. M., \& Elliot, A. J. (1998). Not all personal goals are personal: comparing autonomous and controlled reasons for goals as predictors of effort and attainment. Personality and Social Psychology Bulletin, 24, 546-557.

Sheldon, K. M., \& Elliot, A. J. (1999). Goal striving, need satisfaction, and longitudinal wellbeing: The self-concordance model. Journal of Personality \& Social Psychology, 76(3), 482497.

Sheldon, K. M., \& Houser-Marko, L. (2001). Self-concordance, goal attainment, and the pursuit of happiness: Can there be an upward spiral? Journal of Personality and Social Psychology, $80,152-165$.

Sheldon, K. M., \& Kasser, T. (1995). Coherence and congruence: Two aspects of personality integration. Journal of Personality and Social Psychology, 68, 531-543.

Sheldon, K. M., \& Kasser, T. (1998). Pursuing personal goals: Skills enable progress but not all progress is beneficial. Personality and Social Psychology Bulletin, 24, 546-557.

Sheldon, K. M., Kasser, T., Smith, K., \& Share, T. (2002). Personal goals and psychological growth: Testing an intervention to enhance goal attainment and personality integration. Journal of Personality, 70(1), 5-31.

Sheldon, K. M., Prentice, M., \& Osin, E. (2019). Rightly crossing the Rubicon: Evaluating goal self-concordance prior to selection helps people choose more intrinsic goals. Journal of Research in Personality, 79, 119-129.

Sheldon, K. M., \& Schuler, J. (2011). Needing, wanting, and having: Integrating motive disposition theory and self-determination theory. Journal of Personality and Social Psychology, 101, 1106-1123.

Suddendorf, T., Addis, D.R., \& Corballis, M.C. (2009). Mental time travel and the shaping of the human mind. Philosophical Transactions of the Royal Society, 364, 1317-1324.

Suddendorf, T., \& Corballis, M. C. (2007). The evolution of foresight: What is mental time travel, and is it unique to humans? Behavioral and Brain Sciences, 30, 299-313.

Szpunar, K. K. (2010). Episodic future thought: An emerging concept. Perspectives on Psychological Science, 5, 142-162.

Teimouri, Y., Plonsky, L., \& Tabandeh, F. (2020). L2 grit: Passion and perseverance for second-language learning. Language Teaching Research. https://doi.org/10.1177/1362168820921895.

Vasalampi, K., Salmela-Aro, K., \& Nurmi, J. E. (2009). Adolescents' self-concordance, school engagement, and burnout predict their educational trajectories. European Psychologist, 14(4), 332-341.

\section{Copyrights}

Copyright for this article is retained by the author(s), with first publication rights granted to the Journal.

This is an open-access article distributed under the terms and conditions of the Creative Commons Attribution license (CC BY-NC-ND) (http://creativecommons.org/licenses/by-nc-nd/4.0/). 